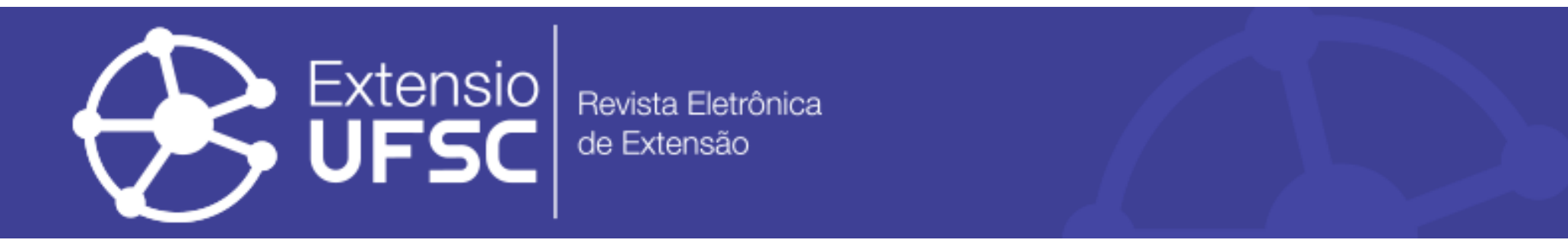

\title{
ESPORTE ADAPTADO NA UFSC: UMA ANÁLISE A PARTIR DAS MANIFESTAÇÕES ESPORTIVAS
}

\author{
Bruna Barboza Seron \\ Universidade Federal de Santa Catarina \\ bruna.seron@ufsc.br \\ Gabriela Fischer \\ Universidade Federal de Santa Catarina \\ gabriela.fischerrs@gmail.com
}

\begin{abstract}
Resumo
A prática esportiva auxilia no desenvolvimento global de pessoas com deficiência. No entanto, essa prática pode ser realizada sob diferentes perspectivas. O presente estudo teve como objetivo analisar as ações dos diferentes projetos de extensão de esporte adaptado na Universidade Federal de Santa Catarina (UFSC), a partir das diferentes manifestações esportivas (educacional; participação e rendimento). Os projetos de extensão de esporte adaptado são desenvolvidos no Centro de Desportos desde 1996 e atualmente são ofertadas práticas de cinco modalidades adaptadas: Atletismo; Goalball; Handebol em cadeira de rodas; Natação e Tênis em cadeira de rodas. Ao fazer a análise, foi possível identificar que todos os projetos desenvolvem ações nas diferentes manifestações esportivas. Considera-se, além disso, que os projetos têm assegurado por meio do esporte, oportunidades de efetivação de inúmeros direitos e de participação social de pessoas com deficiência.
\end{abstract}

Palavras-chave: Esporte Adaptado. Deficiência. Manifestações Esportivas.

\section{SPORT ADAPTED AT UFSC: AN ANALYSIS FROM SPORTS CATEGORIES}

\begin{abstract}
Sports practice assists the general development of people with disabilities. However, this practice can be carried out from different perspectives. The objective of this study was to analyze the actions of the different adapted sports extension projects at Federal University of Santa Catarina (UFSC) from the different categories of sports (educational; participation and performance). The adapted sports extension projects have been developed in the Sports Center since 1996 and currently offer practices of five adapted modalities: Athletics; Goalball; Wheelchair Handball; Swimming and Wheelchair Tennis. When doing the analysis, it was possible to identify that all the projects to develop actions in the different sports categories. It is also considered that the projects have guaranteed, through sport, opportunities for the effective implementation of numerous rights and the social participation of people with disabilities.
\end{abstract}

Keywords: Adapted Sport. Disabilities. Sports Categories.

\section{DEPORTE ADAPTADO EN LA UFSC: UN ANÁLISIS A PARTIR DE LAS MANIFESTACIONES DEPORTIVAS}

\begin{abstract}
Resumen
La práctica deportiva ayuda en el desarrollo global de las personas con discapacidad. Sin embargo, esta práctica puede realizarse bajo diferentes perspectivas. El presente estudio tuvo como objetivo analizar las acciones de los diferentes proyectos de extensión de deporte adaptado en la UFSC a partir de las diferentes manifestaciones deportivas (educación; participación y rendimiento).. Los proyectos de extensión de deporte adaptado se desarrollan en el Centro de Deportes desde 1996 y actualmente se ofrecen prácticas de cinco modalidades adaptadas: Atletismo; Goalball; Balonmano en silla de ruedas; Natación y Tenis en silla de ruedas. Al hacer el análisis fue posible identificar que todos los proyectos desarrollan acciones en las diferentes manifestaciones deportivas. Se considera, además, que los proyectos han asegurado por medio del deporte, oportunidades de efectividad de innumerables derechos y participación social de personas con discapacidad.

Palabras clave: Deporte Adaptado. Discapacidad. Manifestaciones Deportivas.
\end{abstract}




\section{INTRODUÇÃO}

O esporte contemporâneo possui uma série de definições e interpretações. Considerado mundialmente um dos fenômenos socioculturais mais importantes dos últimos dois séculos, o esporte está cada vez mais presente na vida das pessoas. Segundo Bento (1999), o esporte é polissêmico e polimorfo, isto é, assume múltiplos significados e formas. Portanto, o esporte pode ser considerado, além de conteúdo da Educação Física, uma poderosa ferramenta de transformação da realidade. Neste contexto, podemos citar o Esporte Adaptado e o Esporte Paralímpico para pessoas com deficiência.

O Esporte adaptado refere-se ao esporte modificado ou criado para suprir as necessidades especiais das pessoas com deficiência (WINNICK, 2017). O Esporte Paralímpico, por sua vez, compreende modalidades esportivas praticadas por pessoas com deficiência, reconhecidas pelo Comitê Paralímpico Internacional (IPC) e apresentadas em eventos de sua promoção e gerenciamento (ARAÚJO, 2011). O esporte Paralímpico é considerado um ambiente mais restritivo, pois remete a uma das 25 modalidades de verão e as cinco de inverno do programa paralímpico por atletas de rendimento (COSTA; WINCKLER, 2012). Além disso, o processo de classificação esportiva (médica ou funcional) permite que apenas atletas com deficiência mínima, de acordo com critérios esporte-específicos de elegibilidade, participem das competições oficiais (TWEEDY; VANLANDEWIJCK, 2011). Por outro lado, o esporte adaptado é muito mais abrangente, e engloba a prática pautada em diferentes manifestações esportivas.

As manifestações esportivas foram concebidas justamente para contestar o Esporte na perspectiva única do rendimento. Uma série de documentos como "O Manifesto do Esporte" e movimentos como o "Movimento Esporte para Todos" na década de 60 já ampliava o alcance do Esporte no mundo. Porém, o marco para uma nova concepção, foi a publicação da Carta Internacional de Educação Física e Esporte da UNESCO (1978). No Brasil, as manifestações Esporte-Educação, Esporte-Participação e Esporte-Rendimento começaram a ser pensadas por uma comissão presidida pelo professor Manoel Tubino em 1985. Embora a Constituição Federal de 1988 já referenciasse um novo conceito de Esporte, o Brasil permaneceu até 1993 sem uma lei específica. Isso aconteceu na Lei $n^{\circ} 8.672 / 1193$ (Lei Zico) que contemplou o reconhecimento das manifestações esportivas. Depois da Lei Zico, a Lei Pelé ( $\left.\mathrm{n}^{\circ} 9.615 / 1998\right)$ praticamente manteve o texto anterior quanto aos conceitos e princípios (TUBINO, 2010).

A produção intelectual referente às manifestações esportivas é vasta, assim como novas interpretações e novos conceitos. No presente artigo, o texto será pautado seguindo os preceitos 
Esporte adaptado na UFSC: uma análise a partir das manifestações esportivas

e conceitos da legislação vigente (BRASIL, 1998). Neste sentido, as definições das manifestações podem ser interpretadas da seguinte forma (BRASIL, 1998; COSTA \& WINCKLER, 2012):

- O Esporte-Educação pode ser praticado nos sistemas de ensino ou em ambientes assistemáticos de educação. Seu objetivo é proporcionar o desenvolvimento integral da pessoa e a sua formação para o exercício da cidadania. Seus princípios são pautados na inclusão, participação e cooperação. O esporte é o canal para o conhecimento do e pelo corpo. No caso da pessoa com deficiência, permite o acesso às possibilidades de novas formas de movimento ou interação com o meio.

- Esporte-Participação: esta manifestação está relacionada com conceitos de lazer e promoção da saúde. O Esporte-Lazer tem seu foco na possibilidade de usar o esporte como ocupação do tempo livre e na obtenção do prazer. Embora essa manifestação seja mais acessível a todos, a pessoa com deficiência pode não ter acesso ao esporte-Lazer em função de diferentes barreiras. Além disso, o esporte pode ser utilizado com a finalidade de reabilitação ou a manutenção do estado de saúde do praticante. Vale ressaltar que o esporte para pessoas com deficiência surgiu como uma ferramenta de reabilitação na metade do século XX.

- Esporte-Rendimento: é aquele praticado obedecendo a códigos e regras estabelecidos por entidades internacionais. Objetiva a resultados, a vitórias, a recordes, a títulos esportivos, a projeções na mídia e a prêmios financeiros. Essa manifestação está associada à questão do esporte-espetáculo. Nesse ambiente, atletas com deficiência podem ser profissionais e viver por meio de seus ganhos provindos do esporte.

A interpretação das manifestações esportivas mencionadas acima, nos faz refletir e interrogar o quanto e como elas são desenvolvidas nos projetos de extensão do Centro de Desportos (CDS) da Universidade Federal de Santa Catarina (UFSC). Atualmente, o CDS oferece, de forma gratuita, cinco projetos de esportes adaptados para pessoas com deficiência: Atletismo, Handebol, Tênis em cadeira de rodas, Goalball e Natação. No Atletismo e na Natação participam do projeto pessoas com deficiências físicas, visuais, auditivas e intelectuais. No Handebol e Tênis em cadeira de rodas participam somente pessoas com deficiência física, enquanto que no Goalball, somente pessoas com deficiência visual. O público-alvo engloba pessoas da comunidade em geral e também alunos com deficiência da UFSC, totalizando em média 50 alunos nos cinco projetos. Cada projeto é coordenado por um professor do departamento de Educação Física, e conta com auxílio de alunos bolsistas e de voluntários para o planejamento e desenvolvimento das atividades. Vale a pena mencionar que as associações para 
Esporte adaptado na UFSC: uma análise a partir das manifestações esportivas

pessoas com deficiência (ACIC - Associação Catarinense para Integração do Cego; ACESA Associação Catarinense de Esportes Adaptados e AFLODEF - Associação Florianopolitana de Deficientes Físicos) são parceiras e colaboradoras nos projetos. Dado o exposto, o presente estudo tem como objetivo analisar os diferentes projetos de extensão que envolvem o esporte adaptado na UFSC a partir das diferentes manifestações esportivas.

\section{MATERIAIS E MÉTODOS}

Os projetos de extensão de esporte adaptado desenvolvidos no Centro de Desportos da UFSC buscam promover a participação das pessoas com deficiência em práticas esportivas. Esses projetos, anteriormente chamado "Sábado no Campus: Esportes Adaptados", têm sido desenvolvidos no CDS desde 1996 e foram idealizados pelo professor doutor Luciano Lazzaris Fernandes. Essas práticas proporcionam a inserção das pessoas com deficiência na prática esportiva oportunizando a socialização, além de buscar a melhora de sua qualidade de vida por meio de uma prática de lazer (FERNANDES et al., 2011). Atualmente são ofertadas práticas de cinco modalidades adaptadas:

O Atletismo Adaptado é uma modalidade individual que consiste de provas de corrida, de saltos, de lançamentos e de arremessos. O público alvo são pessoas com deficiência física e visual de ambos os sexos, com idade a partir dos 16 anos. As atividades são realizadas três vezes na semana (segunda, quarta e sexta-feira) na pista de atletismo do CDS.

O Goalball é uma modalidade criada exclusivamente para pessoas com deficiência visual que utilizam percepções auditivas e táteis. Trata-se de um jogo coletivo (três jogadores) não invasivo que tem como objetivo arremessar a bola em direção ao gol do oponente respeitando regras específicas de ataque. As atividades acontecem três vezes na semana (terça-feira, quintafeira e sábado) no ginásio dois do CDS.

O Handebol em cadeira de rodas (HCR) é uma modalidade coletiva adaptada do Handebol olímpico. A modalidade é destinada para pessoas com deficiência física e ainda não faz parte do programa paralímpico. Atualmente, se apresenta de três formas: HCR7; HCR4A e HCR4B. Estas divisões consideram jogo de sete e de quatro jogadores com maiores ou menores níveis de funcionalidade. As práticas ocorrem no ginásio três às terças-feiras e no ginásio um no sábado.

A Natação Paralímpica é destinada para pessoas com deficiência visual, física e intelectual. No entanto, o projeto de natação do CDS é ofertado também para pessoas com deficiência 
Esporte adaptado na UFSC: uma análise a partir das manifestações esportivas

auditiva, permitindo a inclusão de qualquer tipo de deficiência. As atividades ocorrem no complexo aquático do CDS duas vezes na semana no período noturno.

O Tênis em cadeira de rodas é uma modalidade destinada a pessoas com deficiência física que tenham dificuldades na locomoção. O jogo é bastante semelhante à modalidade olímpica, sendo a principal diferença, a permissão de dois quiques da bola na quadra antes de ser devolvida ao adversário. A prática de tênis em cadeira de rodas é feita nas quadras de tênis do complexo esportivo do CDS três vezes na semana no período matutino e vespertino.

Os projetos estabelecem relação direta com outros setores da sociedade, como colégios públicos e privados e tem parceria com associações sem fins lucrativos: ACIC - Associação Catarinense para Integração do Cego; ACESA - Associação Catarinense de Esportes Adaptados e AFLODEF - Associação Florianopolitana de Deficientes Físicos. Além disso, os projetos estão sempre envolvidos em eventos sociais propostos pelo município e também clubes como o Serviço Social do Comércio (SESC).

A parceria com as Associações gera importante impacto social, pois, geralmente as pessoas com deficiência que decidem sair de casa e ir em busca de uma vida autônoma procuram primeiro a associação de referência da cidade. Dessa forma, os projetos funcionam como um local em que esse indivíduo pode se encontrar e usufruir de todos os benefícios de praticar um esporte, além de estabelecer relações sociais importantes nesse contexto.

\section{RESULTADOS E ANÁLISES}

Pessoas com deficiência pertencem a uma minoria que sofrem tanto materialmente como social e psicologicamente os efeitos da exclusão. Os participantes dos projetos, por conta de barreiras impostas pela própria sociedade, não possuem as mesmas oportunidades na educação, lazer ou trabalho, tampouco as mesmas oportunidades de práticas esportivas.

A Lei n. 13.146, de 6 de julho de 2015, Lei Brasileira de inclusão da pessoa com deficiência - Estatuto da pessoa com deficiência, afirma ser dever do Estado, da Sociedade e da Família assegurar à pessoa com deficiência com prioridade a efetivação de inúmeros direitos, tais como saúde, educação, cultura, acessibilidade e desporto (BRASIL, 2015). Nesse sentido, o Centro de Desportos (CDS) auxilia no cumprimento dessa Lei, pois busca inserir e oportunizar a estes indivíduos uma prática esportiva que os auxiliem a serem valorizados nos diversos setores da sociedade, contribuindo no ganho de autonomia e independência para buscarem cada vez mais seus direitos na participação social. 
Os diferentes projetos de práticas de esportes para pessoas com deficiência ofertados pelo CDS procuram atingir diferentes desejos dos participantes. Por isso, oferece práticas voltadas para o rendimento (destinado à formação de atletas de alto nível); para a participação (considerando aspectos de promoção da saúde e do lazer) e para a educação (que busca o desenvolvimento integral do indivíduo, a sua formação para o exercício da cidadania).

Apesar de no presente artigo estarmos considerando a análise das manifestações esportivas de maneira separada, assumimos a simbiose existente entre estas, pois os conceitos de uma estão imbricados nas atividades da outra. Além disso, existem discussões a respeito da dimensão educacional que pressupõem que esta existe apenas como um produto da tensão entre a manifestação participação e rendimento, ora deslocando-se mais para uma e ora mais para outra. Ainda afirmam a contínua existência de um conjunto de valores, habilidades, aptidões, conhecimentos e condutas que são aprendidos, consciente ou inconscientemente, na relação estabelecida com o esporte (PIRES; SILVEIRA, 2007; BRACHT, 1997). Portanto, de maneira desafiadora buscaremos discutir aqui os diálogos das ações realizadas nos projetos de extensão com as proferidas manifestações esportivas.

\section{Esportes Adaptados e sua relação com o esporte educacional}

Os projetos de extensão de esporte adaptado da UFSC buscam seu desenvolvimento por meio dos conceitos do esporte educacional que compreendem as atividades práticas no sistema de ensino, evitando-se a seletividade e a hipercompetitividade de seus praticantes, com a finalidade de alcançar o desenvolvimento integral do indivíduo e a sua formação para o exercício da cidadania e a prática do lazer (BRASIL, 1998).

Esses conceitos podem ser vistos nos formatos dos projetos do CDS, desde a forma de ingresso até a permanência dos alunos participantes. Não há critério de seleção de habilidade e/ou desempenho para o ingresso do participante. Há espaço para pessoas com todos os níveis de conhecimento e experiência prática da modalidade. Os mais experientes procuram auxiliar os alunos mais novos no contexto de desenvolvimento dentro da modalidade. O processo de ensino-aprendizagem nos projetos é pensado, portanto, no incentivo da consciência benéfica da convivência em grupo, na cooperação e no respeito das diferenças do e com o outro. Procura-se também nas atividades esportivas ofertadas que valores como respeito às regras e aos deveres como cidadãos sejam explorados. Por exemplo, estimular o zelo com os equipamentos esportivos ofertados, o cuidado com a limpeza e a estrutura utilizada, o compromisso com a assiduidade e a pontualidade. 
Ao se pensar a UFSC como uma Instituição de ensino superior, entende-se essa como espaço para democratização esportiva. Nesse sentido, torna-se compromisso da Educação Física, área contemplada na universidade, a educação com/para o esporte como formação cultural (PIRES; SILVEIRA, 2007) para qualquer pessoa da comunidade.

O diálogo entre Universidade e escola tem sido uma preocupação dos projetos de extensão de esporte adaptado, pois entende a prática esportiva como importante no desenvolvimento global do escolar na medida em que este participa e se apropria de uma cultura corporal de movimento, educando-se para essa cultura ao longo da vida. No entanto, um trabalho apresentado no Seminário Internacional Paralímpico Escolar de 2017, verificou que apenas 24,3\% dos participantes dos projetos de extensão de esporte adaptado da UFSC são pessoas em idade escolar. Ademais, ressaltou-se que esse número ainda continha duas pessoas em idade escolar sem deficiência que participavam do projeto de handebol em cadeira de rodas (SERON; PACHECO; FISCHER, 2017). Essa reflexão é importante, pois se observa uma lacuna no canal de informação e participação de escolares com deficiência nos projetos ofertados na Universidade. Este fato é inquietante, pois seria um espaço importante para proporcionar aos estudantes com deficiência a oportunidade de vivenciar o esporte adaptado e todas as suas possibilidades. Vale ressaltar que alguns desses projetos têm a preocupação de oportunizar a iniciação esportiva e por isso recebem alunos acima dos dez anos de idade.

Embora tenha ocorrido maior envolvimento de discentes com deficiência da UFSC nos últimos anos, a participação desses nos projetos de extensão tem se mostrado tímida. Segundo a Coordenadoria de Acessibilidade Educacional, a UFSC possui 275 (duzentos e setenta e cinco) alunos autodeclarados com deficiência no ano de 2018. Nesse mesmo ano, oito alunos com deficiência da UFSC participaram nos projetos de extensão de esporte adaptado e representaram a universidade nas modalidades de atletismo, natação e judô (Figura 1).

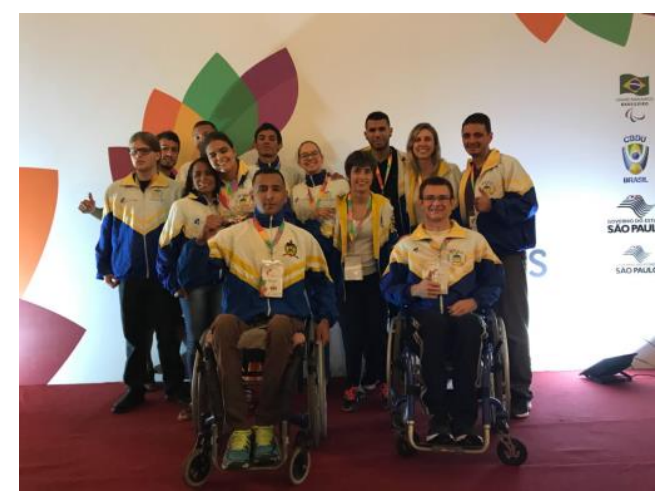

Figura 1. Delegação da Universidade Federal de Santa Catarina nos Jogos Paralímpicos Universitários (2018) 
Para incentivar a participação de alunos com deficiência de Instituições do Ensino Superior em práticas esportivas, o Comitê Paralímpico Brasileiro (CPB) em parceria com a Confederação Brasileira do Desporto Universitário (CBDU) tem organizado os Jogos Paralímpicos Universitários (JPU), que teve sua terceira edição em 2018. Como objetivos educacionais, esses Jogos pretendem utilizar a prática esportiva como fator de integração e intercâmbio sociocultural e desportivo entre estudantes universitários e contribuir para o desenvolvimento integral do estudante universitário como ser social, autônomo, democrático e participante, estimulando o pleno exercício da cidadania através do esporte (CPB,2018).

Nessa perspectiva, as atividades esportivas oferecidas aos participantes procuram ter caráter educacional e concorda com o Programa Segundo Tempo Universitário (BRASIL, 2017) que tem como objetivo o desenvolvimento de jovens discentes, de forma a favorecer a consciência de seu próprio corpo, explorar seus limites, aumentar as suas potencialidades, desenvolver seu espírito de solidariedade, de cooperação mútua e de respeito pelo coletivo.

Esses princípios educacionais podem ser evidenciados na fala de uma das alunas com deficiência da UFSC que representou a Instituição nos JPU:

\begin{abstract}
"Essa foi uma das experiências mais gratificantes em que participei nos últimos tempos, apesar de participar de um esporte que é basicamente individual estávamos todos conectados em uma só energia coletiva e muito positiva, foi muito bom conhecer pessoas novas e melhor ainda foi conhecer os meus limites sobre a perspectiva daquilo que está ao meu alcance em fazer ou não. Espero ter mais oportunidades como essa e torço para que muitos mais universitários com deficiência também conheçam esse lado do esporte para que futuramente tenham essa experiência que nós tivemos" (Relatório de Viagem, 2018 - MEDINA, 2018).
\end{abstract}

Também é reforçado em outra declaração abaixo o quanto é possível, por meio do esporte, o reconhecimento da valorização das potencialidades do aluno com deficiência e a consciência do potencial de contribuição para a formação pessoal.

\begin{abstract}
“(...) agora, sigo com a certeza de que tenho potencial para melhorar em muitas coisas e vou me esforçar ao máximo para tanto. (...) foi uma experiência incrível, formativa e realmente transformadora na minha trajetória como estudante da UFSC e para minha jornada como atleta em desenvolvimento" (Relatório de Viagem, 2018 - SANTIAGO, 2018).
\end{abstract}

Por último, foi possível identificar entre os participantes a percepção sobre buscar ser melhor, sobre superar-se. Compreender que sua deficiência não pode limitá-lo, não pode ser motivo para não lutar pelos seus direitos.

“(...) vai ficar na recordação de cada um que esteve presente bem como motivar a todos a serem melhores e buscarem, independente da dificuldade, a superação, e é esta a palavra que quero levar para minha vida depois de vivenciar tudo isso que ocorreu em apenas 72 horas." (Relatório de Viagem, 2018 - DE BARROS, 2018). 
Esporte adaptado na UFSC: uma análise a partir das manifestações esportivas

Vale destacar, em suma, que as práticas diárias dos projetos servem como espaço de debates sobre os direitos da pessoa com deficiência na sociedade. Para além disso, os projetos também se comprometem na construção educativa de atitude sobre a deficiência para pessoas que estão afora dos muros da universidade. Por isso, existem iniciativas de colaboração com ações nos diversos setores da sociedade.

A relação com as escolas públicas e privadas, por exemplo, se dá por visitas de turmas dos colégios de Florianópolis aos treinos e também com a ida dos atletas dentro dessas escolas com apresentações, conversas e divulgação da modalidade e do projeto em si (Figura 2). Colocar as crianças e jovens em contato com atletas com deficiência e com o esporte adaptado, auxilia na mudança de percepção sobre a deficiência, diminuindo atitudes negativas e ressaltando as potencialidades dos indivíduos com deficiência na sociedade

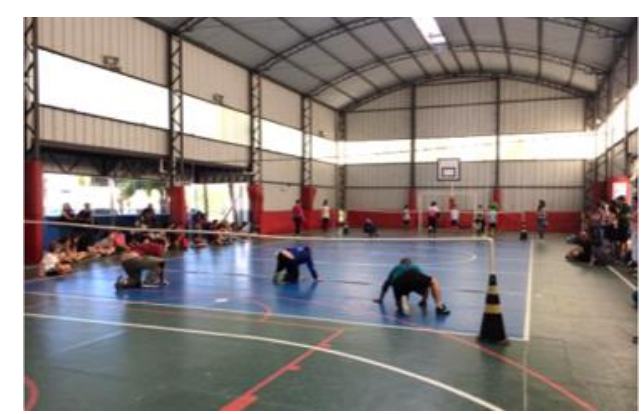

Figura 2. Participação dos participantes do projeto numa escola privada

As participações em eventos sociais contribuem para a valorização da pessoa com deficiência. No último ano (2017), por exemplo, foram realizadas apresentações da modalidade em uma tarde de sábado na beira-mar norte (Figura 3). Centenas de pessoas pararam para olhar, assistiram, conheceram e vivenciaram modalidades antes desconhecidas. Muitos ficaram impressionados com as habilidades das pessoas com deficiência no jogo e nesse momento já não olhavam mais para a limitação de não enxergar ou não andar. Ações assim, proporcionadas por entidades, associações e prefeituras certamente contribuem para a evolução da inclusão e educação tão emergente em nossa sociedade.
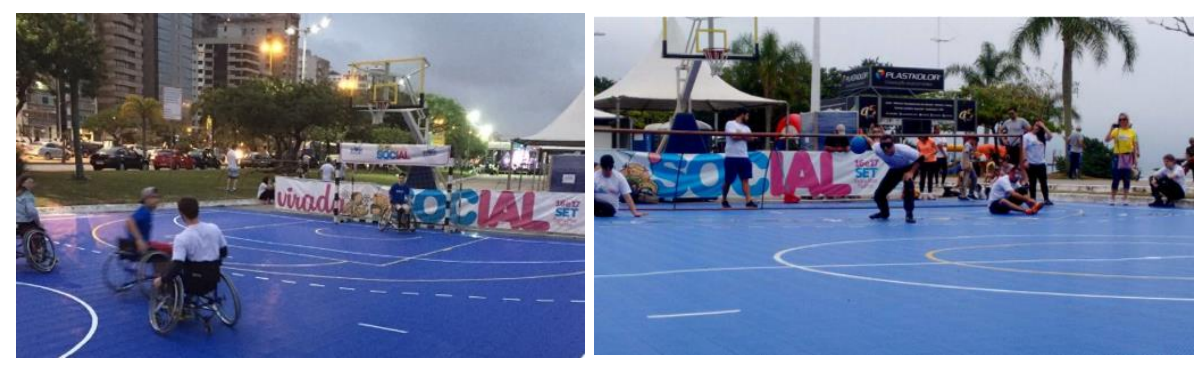
Esporte adaptado na UFSC: uma análise a partir das manifestações esportivas

Figura 3. Apresentação das modalidades na Beira Mar no evento Virada Social

\section{Esportes Adaptados e sua relação com o esporte-participação}

A manifestação esportiva denominada de participação está preocupada com a integração dos praticantes na plenitude da vida social, na promoção da saúde, lazer e educação. Nesse contexto, os projetos de esporte adaptado do CDS atendem esses princípios quando se preocupam com os aspectos biopsicossociais de seus participantes. Nos cinco projetos mencionados são observados objetivos que buscam favorecer o desenvolvimento de habilidades sociais como o exercício da autoconfiança, da autossuficiência, da cooperação e da participação, contribuindo para a promoção da saúde dos participantes.

Dados do IBGE (2010) indicam que 23,9\% da população no Brasil apresentam algum tipo de deficiência. Embora não existam dados oficiais, um número mais preocupante é que se estima que apenas 10\% dessa população pratiquem algum tipo de atividade física regular (SOLER, 2005; GUTIERRES et al., 2010). Diversas são as barreiras encontradas para essa participação sendo a oferta de programas específicos, umas das principais encontradas. Um estudo de Biduski et al. (2016) observou que os participantes dos projetos de extensão de esporte adaptado da UFSC percebem mais facilitadores do que barreiras. Dentre os principais facilitadores destacam-se a simpatia e o conhecimento do profissional, o apoio familiar e o de amigos. Já em relação às barreiras, a presença de lesões físicas, o clima e a distância do local de prática foram as mais apontadas.

Algumas pesquisas foram realizadas pelos estudantes de graduação do curso de educação física e trouxeram resultados importantes do envolvimento dos participantes nos projetos de esportes adaptados. Um estudo realizado com 12 atletas da equipe masculina de Goalball da UFSC investigou a percepção de qualidade de vida por meio do questionário National Eye Institute Visual Function Questionnaire (NEI-VFQ - 25) que avalia o impacto da perda visual na qualidade de vida e apresenta escore de 0 a 100 pontos (AZEVEDO, 2017). Os resultados apontam para uma percepção positiva da qualidade de vida destes atletas que tiveram melhores resultados nos subdomínios: independência; capacidade de realização das atividades da vida diária; saúde mental e geral e especialmente nos aspectos sociais, que atingiu um escore de 92. Esses resultados afirmam o fato de que estar envolvido nessas atividades esportivas pode contribuir para sua qualidade de vida e saúde. De forma negativa, foi observado que grande parte dos sujeitos está com sobrepeso e essa variável apresentou correlação negativa com a percepção de saúde geral. Estes dados alertam para o fato de serem necessárias ações educativas para o controle do peso e questões nutricionais destes participantes. 
Esporte adaptado na UFSC: uma análise a partir das manifestações esportivas

Outro estudo teve como objetivo compreender a contribuição da participação no Goalball como um fator de promoção de saúde na percepção de participantes com deficiência visual praticantes da modalidade na UFSC (DE OLIVEIRA et al., 2017). Nos aspectos físicos, todos os estudantes relataram melhora na força, resistência, agilidade e velocidade, tanto na prática da modalidade quanto nas atividades cotidianas. Além disso, notaram-se mais magros, sendo que mostraram estar mais preocupados com sua alimentação. Para os aspectos psicossociais evidenciaram uma melhor relação com seus colegas, amigos e família; e aguns relataram buscar mais autonomia e independência em sua mobilidade diária. Um dos participantes relatou que nunca havia pegado transporte urbano de maneira autônoma e que o envolvimento dele na prática pôde proporcionar essa ação.

Da mesma maneira foram observados impactos positivos também em participante do projeto de Atletismo Adaptado. Na percepção da mãe do participante houve aumento na responsabilidade e disposição do aluno, além de melhora considerável na agilidade e mobilidade dos membros superiores. Ainda foi relado por ela melhor entrosamento e quebra de barreiras de discriminação no convívio escolar. Já na visão do participante houve aumento de agilidade e força de seus membros superiores, além de melhor aceitação e inclusão no ambiente escolar, promovendo o seu bem-estar (ANTUNES et al., 2017).

Mais do que benefícios para as pessoas com deficiência, os projetos de extensão de esporte adaptado também contribuem para o bem-estar, e proporcionam uma prática de lazer para as pessoas sem deficiência. De maneira mais evidente, no projeto de Handebol em Cadeira de Rodas participam pessoas sem deficiência que sentam na cadeira de rodas e jogam Handebol com aqueles com deficiência. Dessa forma, amigos, familiares, alunos, pessoas da comunidade em geral têm oportunidade de praticar a modalidade juntamente com aqueles que são elegíveis para a prática esportiva. Essa experiência parece muito importante pois, proporcionar experiências similares as de pessoas com deficiência pode ser um método interessante para sensibilizar socialmente pessoas sem deficiência. Essa prática pode fazê-los refletir mais sobre se colocar no lugar do outro, sobre compreender o quanto uma prática esportiva facilita na igualdade de condição e na integração da pessoa em um grupo (ROBLES-RODRIGUEZ et al, 2017; GRENIER; KEARNS, 2012).

Além dos estudos acima mencionados que mostraram de maneira clara a importância desta prática na vida destas pessoas, considera-se os momentos de práticas um espaço para o encontro com o outro. Um espaço em que são desenvolvidos laços de respeito e amizade, e um espaço em que elas, as pessoas com deficiência, podem sim, exercerem participação social ativa por meio do esporte. 
Esporte adaptado na UFSC: uma análise a partir das manifestações esportivas

\section{Esportes Adaptados e sua relação com o esporte rendimento}

O esporte Rendimento é aquele no qual o resultado da competição passa a ter uma relevância central no processo e a melhora do desempenho por meio do treinamento esportivo é o objetivo principal. A análise desta manifestação é bastante complexa considerando o contexto do esporte paralímpico. Quando o atleta com deficiência compete em eventos nacionais e internacionais, a manifestação principal é o rendimento ou alto rendimento; porém aspectos educacionais, de saúde e lazer estão presentes, mesmo que em menor grau (COSTA \& WINCKLER, 2012).

A legislação vigente define que atletas que participam de competições nacionais e internacionais são atletas de rendimento (BRASIL, 1998). Porém, no paradesporto existe um viés em relação a essa definição. Em comparação aos atletas sem deficiência, aqueles que têm deficiência, destacam-se com pouco tempo de prática na modalidade e com desempenho inferior, pelo menos em nível regional e nacional universitário. Isso significa que a trajetória de um atleta com deficiência é bastante diferente da de um atleta sem deficiência. Foi possível observar essa particularidade nos Jogos Paralímpicos Universitários, onde a maioria dos nossos alunos de nível iniciante conquistaram medalhas. A equipe da UFSC foi composta por onze pessoas: oito atletas com deficiência, dois atletas guias e um staff que participaram das modalidades de atletismo, judô e natação. Ao total, foram 15 medalhas em diferentes provas e classes esportivas.

Uma característica importante na manifestação Esporte-Rendimento é a classificação esportiva. Enquanto que nas manifestações Esporte-Educacional e Esporte-Participação ela possua menos relevância, no Esporte-Rendimento ela é indispensável (COSTA; WINCKLER, 2012). O objetivo da classificação esportiva é minimizar o impacto da deficiência no resultado da competição e desta forma garantir equidade de disputa (TWEEDY; VANLANDEWIJCK, 2011). O fato de cada modalidade paralímpica apresentar uma série de classes esportivas, que consideram o nível de funcionalidade em um amplo espectro de deficiências, também permite que alguns atletas subam no pódio com um nível inferior de envolvimento e dedicação comparado ao esporte de alto rendimento convencional.

No entanto, em eventos nacionais como o Circuito Loterias Caixa que envolve Atletismo, Halterofilismo e Natação e outros campeonatos brasileiros de modalidades Paralímpicas o nível de desempenho exigido é maior. No projeto "Atletismo Adaptado: iniciação ao treinamento", podemos citar a participação de dois atletas com paralisia cerebral que já conquistaram resultados expressivos em provas nacionais e internacionais. Esses atletas possuem uma significativa carga de treinamento com acompanhamento sistematizado por parte do treinador. Ainda, além da 
Esporte adaptado na UFSC: uma análise a partir das manifestações esportivas

preparação física e tática, contam com a preparação psicológica e acompanhamento de nutricionista. Outro destaque é o projeto de Goalball. A equipe masculina que treina no projeto ficou em sétima posição no Campeonato Brasileiro de Goalball e conquistou vaga para a série B. Atualmente, o treinador da equipe, que iniciou como aluno de graduação e permaneceu 14 anos dedicando-se ao projeto, é o preparador físico da seleção brasileira feminina de Goalball, a qual conquistou o bronze no último mundial. A equipe da UFSC também conta com um atleta que competiu na seleção masculina de Goalball nas Paralimpíadas de 2008, na China. Em competição de nível nacional, um atleta do projeto do tênis em cadeira de rodas, obteve a terceira colocação no geral na Copa das Federações de Tênis em cadeira de rodas disputada esse ano em São Paulo.

Considerando os eventos regionais, o Handebol em cadeira de rodas conquistou o terceiro lugar no Jogos Abertos Paradesportivos de Santa Catarina (PARAJASC) enquanto que o Goalball levou o ouro no feminino e no masculino em 2017. Ainda, o Atletismo ocupou o sétimo lugar para deficiência física no masculino e feminino, segundo lugar para deficiência visual no masculino e quarto lugar no feminino.

De modo geral, a presente análise revelou que a manifestação esporte-rendimento é bastante expressiva nos diferentes projetos, aparecendo em menor grau no projeto de Natação. Este achado pode estar relacionado ao fato da piscina Olímpica do CDS estar em manutenção, dificultando o treinamento que hoje é realizado na piscina adaptada. Entre outros problemas, também observamos a dificuldade em manter o esporte-rendimento vivo dentro da universidade, seja pela falta de incentivo financeiro, recursos humanos e ambiente estrutural. $O$ apoio financeiro para participação nas competições mencionadas acima vem, na grande maioria, das associações. De qualquer maneira, entendemos que o esporte-rendimento, assim como as outras manifestações esportivas para pessoas com deficiência, são vitais. É também por meio desta manifestação que os atletas evidenciam suas potencialidades e seu empoderamento.

\section{CONSIDERAÇÕES FINAIS}

O presente estudo analisou os diferentes projetos de extensão que envolvem o esporte adaptado na UFSC a partir das manifestações esportivas esporte-educacional, esporteparticipação e esporte-rendimento. Apesar da análise das manifestações terem sido de maneira separada, foi assumida a simbiose existente entre estas, pois os conceitos de uma estão imbricados nas atividades da outra. A partir da presente análise, conclui-se que as três manifestações esportivas são trabalhadas em todos os cinco projetos, variando de menor a maior grau para cada um deles. Isso mostra que os projetos de extensão comportam diferentes 
Esporte adaptado na UFSC: uma análise a partir das manifestações esportivas

objetivos e isso impacta diretamente no número de pessoas com deficiência interessadas e engajadas nas atividades. No entanto, vários aspectos ainda precisam ser melhorados, como o número de escolares nos projetos, investimento para manutenção de recursos humanos e materiais e acessibilidade nos locais de prática. Concluindo, mais do que uma simples prática esportiva, os projetos de esporte adaptado da UFSC formam cidadãos, promovem a saúde e o bem-estar e abrem a possibilidade para a formação de atletas e treinadores do esporte paralímpico.

\section{REFERÊNCIAS}

ARAÚJO P.F. Desporto adaptado no Brasil. São Paulo: Phorte; 2011

BENTO, J.O.O. Contexto e Perspectivas. In. BENTO, J.O.; GARCIA, R.; GRAÇA, A. Contextos da Pedagogia do desporto. Lisboa: Horizonte, 1999.

BIDUSKI, G. M.; SERON, B. B. ; BERTOLI, J. ; ROSSATO, M. ; FREITAS, C. L. R. . Barreiras e facilitadores para a prática de esportes adaptados na Universidade Federal de Santa Catarina. In: V Congresso Paradesportivo Internacional, 2016, Belo Horizonte - MG. Anais do V Congresso Paradesportivo Internacional, 2016. p. 481-486.

BRACHT, Valter. Sociologia crítica do esporte: uma introdução. Vitória: Ed.UFES, 1997.

BRASIL. Diretrizes do Programa Segundo Tempo Universitário 2017. Disponível em $<$ http://www.esporte.gov.br/arquivos/snelis/2017/diretrizes pst universitario 2017.pdf $>$ Acesso em: 20 de ago de 2018.

BRASIL. LEI N $\mathbf{N}^{\mathbf{1}}$ 13.146, DE 6 DE JULHO DE 2015. Disponível em: <http://www.planalto.gov.br/ccivil_03/_ato2015-2018/2015/lei/113146.htm> Acesso em: 05 de set de 2018.

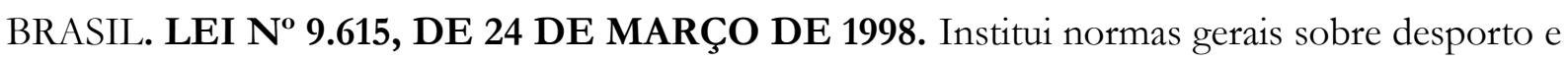
dá outras providências. Disponível em: < http://www.planalto.gov.br/ccivil 03/LEIS/L9615consol.htm> Acesso em: 01 de set de 2018.

COMITÉ PARALÍMPICO BRASILEIRO. Regulamento dos Jogos Paralímpicos

Universitários 2018. Disponível em:

http://www.cpb.org.br/documents/20181/94007/Regulamento+Jogos+Parali\%CC\%81mpicos +Universita $\%$ CC $\% 81$ rios $+2018 /$ c778237a-fceb-45e2-be5a-55738e9f1df0 Acesso em: 30 de ago de 2018.

COORDENADORIA DE ACESSIBILIDADE EDUCACIONAL. CAE. Dados sobre Estudantes com Deficiência. Disponível em: http://cae.ufsc.br/dados-sobre-estudantes-comdeficiencia/ Acesso em: 08 de set de 2018.

COSTA A.M. \& WINCKLER C.A Educação Física e o Esporte Paralímpico. IN: Esporte Paralimpico. São Paulo: Atheneu 2012. 
Esporte adaptado na UFSC: uma análise a partir das manifestações esportivas

DE BARROS, M. Relatório de Viagem dos Jogos Paralímpicos Universitários enviado à PROEX, 2018. Mensagem enviada para proex@,contato.ufsc.br, 2018.

FERNANDES, L. L.; RODRIGUES, L. A.; VASCONCELOS, M. P.; SCHERER. R. L. Projeto Sábado no Campus: Esportes Adaptados e o goalball na formação acadêmica. Extensio: Revista eletronica de extensão, ano 8, n. 11, p. 32-41, 2011.

GUTIERRES FILHO P, MENEZES VR, VARGAS CR, SILVA R, ROSA IC. Revisão sistemática da produção científica relacionada à qualidade de vida e atividade física de pessoas com deficiência visual. Rev Digital Buenos Aires, v.14, p.142, 2010.

IBGE. Censo Demográfico 2010 - Características Gerais da População. ... Disponível em: http://www.censo2010.ibge.gov.br.

MEDINA, I. Relatório de Viagem dos Jogos Paralímpicos Universitários enviado à PROEX. Mensagem enviada para proex@,contato.ufsc.br, 2018.

OLIVEIRA, T. D.; FISCHER, G.; SCHERER, R. L. ; SERON, B. B. . Esporte como fator de promoção de saúde na percepção de 3 atletas em nível escolar. In: Seminário Internacional Paralímpico Escolar, 2017, São Paulo. Anais, 2017. v. 1. p. 78-78.

PIRES, G. D. L.; SILVEIRA, J. Esporte Educacional... Existe? Tarefa e compromisso da educação física com o esporte na escola. In: SILVA, Mauricio Roberto (org.). Esporte, Educação, Estado e Sociedade. Chapecó: Argus, 2007.

SANTIAGO, A. Relatório de Viagem dos Jogos Paralímpicos Universitários enviado à PROEX. Mensagem enviada para proex@,contato.ufsc.br, 2018.

SERON, B. B.; PACHECO, R.; FISCHER, G. Prática de Esporte Adaptado na Universidade Federal de Santa Catarina: Onde estão os escolares?. In: Seminário Internacional Paralímpico Escolar, 2017, São Paulo. Anais, 2017. v. 1. p. 45-45.

SOLER, R. Educação física inclusiva na escola em busca de uma escola plural. 1. ed. Rio de Janeiro: Sprint, 2005.

TWEEDY, S.M.; VANLANDEWIJCK, Y.C. International Paralympic Committee position stand--background and scientific principles of classification in Paralympic sport. $\mathrm{Br} \mathrm{J}$ Sports Med. 2011;45: 259-269.

TUBINO, M.G. Estudos brasileiros sobre o esporte: ênfase no esporte-educação. Maringá: Eduem, 2010.

WINNICK, J.; PORRETTA, D. Adapted Physical Education and Sport $6^{\circ}$ edition Champaign: Human Kinetics, 2017.

Recebido em: 17/09/2018

Aceito em: 27/09/2018 